\title{
Akten van de generale kapittels van de kartuizerorde in het Rijksarchief te Brugge
}

\author{
J.De Grauwe
}

In het Rijksarchief van Brugge deden de heer M. Nuyttens, archivaris, en ikzelf enkele merkwaardige ontdekkingen. Onafhankelijk van elkaar vonden we in uiteenlopende fondsen documenten die eigenlijk bij elkaar horen nl. de cartae of chartae van de generale kapittels van de kartuizerorde.

Wat is een carta? Het is het document dat opgesteld wordt op het einde van het generaal kapittel en waarin de beslissingen worden opgesomd die genomen zijn tijdens dit kapittel. Het vermeldt de religieuzen en de weldoeners die overleden zijn sinds het voorgaande kapittel en preciseert de gebeden en missen die de monniken moeten zeggen of celebreren voor de rust van hun zielen. Het eerste generaal kapittel dateert van 1140. Wegens de uitbreiding van de orde en het verlangen naar centralisatie o.m. om een gelijklopende interpretatie te hebben van de Consuetudines ${ }^{1}$ van Guigo, prior van de Grande Chartreuse omstreeks 1127, vroegen de priors van Portes, Les Ecouges, Durbon en Arvières aan Anthelmus om een kapittel samen te roepen in de Grande Chartreuse. Het is de hoogste autoriteit van de orde. Om het jaar (nu echter om de twee jaar) komen de priors en de vicarissen van de monialenkloosters samen in de Grande Chartreuse voor dit kapittel, dat begint op de vierde zondag na Pasen. Het bepaalt de wijzigingen in het beleid en de observanties van de orde. De genomen beslissingen treden onmiddellijk in voege, maar worden slechts definitief na de bevestiging ervan door het volgende generaal kapittel.

De akten die we vonden in het Rijksarchief van Brugge bevinden zich in het fonds Aanwinsten nr. 593 (Aanw.), in het fonds OudKerkarchief (OKA) nr. 338 en in het fonds Cumulus Ecclesiasticus (CE). Wij zullen bij de opsomming van de gegevens iedere keer dit fonds vermelden bij het jaar waarin de carta (c.) tot stand kwam. Voor het fonds CE volgt het nummer waaronder de carta voorkomt. Deze cartae zijn niet de volledige oorspronkelijke documenten, maar

1 De Consuetudines van Guigo zijn in feite de eerste officiële wetgeving van de kartuizerorde. Het zijn dus de statuten van de Orde die wegens nieuwe omstandigheden of onder druk van de ervaring doorheen de eeuwen aanpassingen vergden. 
de kopies die vervaardigd werden voor de Dietse provincie (provincia Teutoniae, soms teutonica) van de kartuizerorde. De kartuizen van Brugge en Nieuwpoort behoorden tot die provincie. Heel vaak zien we een kruisje of een ander teken voor een vermelding die van toepassing was op een van die kloosters. Soms is die tekst onderstreept. Het zijn dus duidelijk kopies die bestemd waren voor deze conventen. Onze cartae waren veelal niet bestemd voor slechts één klooster, want meer dan eens wordt op het einde van de carta meegedeeld naar welk klooster ze moest verder worden gezonden. We zullen dat ook vermelden bij de betreffende cartae.

Alle cartae zijn opgesteld volgens eenzelfde schema:

aankondiging van het generaal kapittel en datum van de zondag van Septuagesima van het volgende jaar;

de algemene tricenaria;

de overlijdens: hoogwaardigheidsbekleders, koormonniken, conversen, donaten, monialen, seculiere priesters, leken ("seculares") en vrouwen;

missen van de H. Geest en Onze-Lieve-Vrouw;

status van de huizen uit de Dietse provincie in chronologische volgorde van hun incorporatie ${ }^{2}$ in de Orde;

eventuele wijzigingen, aanpassingen, beschikkingen i.v.m. de statuten en de observanties.

De volgorde waarin de overleden kartuizers voorkomen is ongeveer de volgende:

eerst de monniken die een functie uitoefen(d)en, dan de gewone koormonniken, de conversen, de donaten, de monialen. Ze worden vermeld volgens de provincie waartoe ze behoorden en in deze provincie in hun klooster volgens de datum van incorporatie. Er zijn weliswaar heel wat uitzonderingen op deze volgorde.

Alle gegevens die in de cartae voorkomen met betrekking tot de WestVlaamse kartuizen, worden in chronologische orde meegedeeld.

\section{Functies in de kartuizerorde}

Hieronder vermelden we de verschillende functies en soorten kartuizers die in de cartae voorkomen en geven er de inhoud van weer.

2 Incorporatie is de officiële erkenning dat dit bepaalde huis tot de Orde behoort. 
Prior: Hij is het hoofd van het huis en de gemeenschappelijke vader van zijn monniken. Hij is verantwoordelijk voor het tijdelijk, maar vooral voor het geestelijk welzijn van allen.

Rector: Hij is de voorlopige overste van een huis, meestal benoemd om een nieuwe stichting te begeleiden; soms ook overste in een kartuis waar voor een bepaalde tijd geen prior is, wegens omstandigheden.

Vicaris: Onmiddellijke helper van de prior. Hij vervangt deze tijdens diens afwezigheid. Ook wanneer de functie van prior vacant is, na overlijden of ontheffing.

Procurator: De verantwoordelijke van de administratie van het klooster. Hij staat onder het toezicht van de prior. Meestal is hij de onmiddellijke overste van de broeders, zowel op geestelijk als op tijdelijk vlak.

Coadjutor: Deze term is eigenlijk niet officieel. Naar gelang het tijdstip was hij helper van de procurator; later was hij de geestelijke begeleider van retraitanten of bezoekers. Bij de monialen, was hij de rechterhand van de vicaris.

Sacrista: Verantwoordelijke van de kerk en van alles wat de liturgie betreft: meubels, boeken, gewaden...Aanvankelijk was hij de verantwoordelijke van de bibliotheek.

Antiquior: In principe, de oudste profes van het huis. Hij vervangt de prior en de vicaris bij hun afwezigheid.

Senior: Niet-officiële titel, die men soms ontmoet in de cartae. Duidt nu eens de antiquior aan, dan weer de oudste in jaren.

Monachus: Is de kartuizer die een cel van het grote pand bewoont en die alle officies bidt hetzij in de cel, hetzij in de kerk. Sinds de twaalfde eeuw wordt hij priester.

Conversus of convers : Is de kartuizer die vooral handenarbeid verricht. Hij kent minder eenzaamheid dan de monachus of koormonnik. Het officie van de convers was verschillend van dat van de monniken, nu echter heeft de convers ook de mogelijkheid hetzelfde officie te bidden als de koormonnik. 
Donatus of donaat : Een verzachte vorm van convers. Hij is niet verbonden aan een huis door geloften, maar door een contract. De donaat legt geen professie af, maar het contract dat hij ondertekent is de donatio, die dus enigszins overeenkomt met de professie.

Bij de monialen bestaat er een priorin, te vergelijken met de prior bij de monniken, een onderpriorin, enigszins te vergelijken met de vicaris en een celleraria die zowat de procurator is van het huis.

Reverendus Pater: Is de titel die in de Orde gegeven wordt aan de prior van de Grande Chartreuse, tevens prior-generaal van de Orde.

Visitator: Het generaal kapittel (of soms Révérend Père) duidt twee priors aan om in elk huis van de kartuizerprovicie de canonieke visitatie doen. De visitator is de eerste verantwoordelijke en wordt bijgestaan door de convisitator.

Convisitator: Is de helper van de visitator, omdat elke visitatie door twee priors moet gedaan worden.

Professus: Elke koormonnik en convers die de drie monastieke geloften aflegt in een bepaald huis. Vroeger gebeurde het wel eens dat een monnik een tweede professie aflegde in een ander huis waar hij een nieuwe verblijfplaats had gekregen.

Hospes: Een monnik die, meestal tijdelijk, naar een ander kartuizerklooster verplaatst werd om bepaalde redenen. Vroeger legde die soms in dat huis een tweede professie af.

Wat het officie betreft van de conversen en donaten: dat was vroeger vooral samengesteld uit onzevaders en weesgegroeten.

Andere termen die voorkomen in de cartae:

Tricenarium: Een mis ter intentie van de overledene gedurende dertig opeenvolgende dagen, met agenda.

Monachatum: Tricenarium, anniversarium en volledig psalter.

Anniversarium: Dodenofficie en een mis op de verjaardag van het 
afsterven. In het calendarium van elk huis van de Orde schrijft men de dag in waarop dit moet geschieden.

Agenda: Recitatie in het koor van vespers, metten en lauden van het dodenofficie.

Breve: Elke monnik reciteert het dodenofficie. In elk huis wordt een requiemmis opgedragen.

\section{De West-Vlaamse kartuizenkloosters}

De Brugse kartuis werd gesticht in 1318 op Sint-Kruis. In 1578 werd die kartuis met de grond gelijkgemaakt. De monniken hernamen het conventueel leven binnen Brugge vanaf 1584. In 1783 schafte Jozef II alle "onnutte" kloosters af, ook de twee kartuizen van Brugge.

Sheen Anglorum is de voortzetting van het klooster van Sheen in Engeland dat in 1556 alle Engelse kartuizers huisvestte. In 1559 werden de kartuizers definitief uit Engeland verjaagd en de monniken vonden een toevlucht bij hun Brugse ordebroeders. In 1569 vormden ze een autonoom klooster dat in 1578 echter ook uit Brugge moest vertrekken. Na een moeilijke en avontuurlijke tocht doorheen Noord-Frankrijk, kwamen ze via Namen terecht bij de Leuvense kartuizers. Daar bleven ze slechts korte tijd en gingen naar Antwerpen, waar ze reeds in 1591 moesten weggaan.Ze konden zich vestigen in Mechelen. In 1626 vonden ze een nieuw onderkomen in Nieuwpoort, waar ze bleven tot aan de opheffing in 1783 . We vermelden dit klooster als "Sheen" en niet onder zijn officiële titel "Sheen Anglorum Neoporti".

Het monialenklooster Sint-Anna werd gesticht op Sint-Andries in 1348. In 1580 moesten ook de zusters hun convent verlaten en ze vestigden zich binnen Brugge tot de opheffing in 1783. Ze hernamen hun communiteitsleven in 1790, maar in 1796 werd hun klooster door de Franse wetten definitief opgeheven.

Deze bijdrage is een aanvulling bij de artikelen die al eerder over de kartuizers werden gepubliceerd (zie de selectieve bibliografie). Het zijn slechts bouwstenen voor verder onderzoek. 


\section{7 (Aanw. 593)}

Overlijdens

Josephus Slade deed professie in Sheen, toen nog binnen Brugge, in 1576 en overleed in Mechelen op 15.8.1616.

Magdalena Janssen was als donate zeker in 1580 reeds in S. Anna. Overleed in 1616/1617.

Wijzigingen

Joannes Richard, profes van Brussel in 1612, na studies aan de Universiteit van Leuven. Van 1615 tot 1617 was hij vicaris van Brugge en in 1617 werd hij er procurator benoemd.

Guido Heynkens deed professie te Brugge in 1574. Na een verblijf als vicaris in Würzburg, werd hij procurator en vicaris te Brugge. In 1617 werd hij opnieuw vicaris, na alweer procurator te zijn geweest.

\section{8 (Aanw. 593)}

Overlijdens

Joannes Carr, profes van Sheen, overleed in Mechelen op 12.2.1618. Georgius Brown, convers van Sheen, overleed in Mechelen op 12.9.1617.

\section{Wijzigingen}

Geen.

\section{9 (Aanw. 593)}

\section{Overlijdens}

Guido Heynkens overleed in 1618 in Brugge, als vicaris.

\section{Wijzigingen}

Joannes Baronaige, profes van Leuven in 1604, werd door de visitator tot vicaris van Brugge aangesteld na de dood van Guido Heynkens.

\section{0 (Aanw. 593)}

\section{Overlijdens}

Robertus Mallory was vicaris van Sheen in 1611, toen hij er prior werd benoemd. Hij overleed in Mechelen op 31.3.1620.

Joannes Suertis, profes van Sheen in 1572, overleed als antiquior van dat huis op 2.4.1620.

Joannes Marensis, profes van Luik, was vicaris in Brugge (16091616). Tot aan zijn dood in 1620 was hij er sacrista. 


\section{Wijzigingen}

Joannes Marensis werd als sacrista van Brugge opgevolgd door Petrus Vernoort, profes van Lier.

Thomas Hallowes, profes en procurator van Sheen, werd er tot prior benoemd in 1620 .

Daniel Tuer, profes van Sheen, ging in 1620 naar Lier.

\section{c. 1621 (CE 1502)}

\section{Overlijdens}

Elisabeth, donate. Het is Elisabeth Pykevet die zeker in 1580 reeds in Sint- Anna was.

Didacus Maldonato deed professie in Sheen omstreeks 1598. Hij overleed als hospes in Montalegre, Spanje, op 20.3.1621. Vermoedelijk was hij van Spaanse afkomst. In 1613 was hij een lastige monnik. Werd hij daarom naar Spanje gestuurd?

\section{Wijzigingen}

Bertinus Oliver, profes van Sheen, wordt van Sheen naar Brugge gestuurd.

Gerardus Eligius Radelet wordt vanuit Sint- Anna teruggestuurd naar zijn huis van professie, Brussel.

De vicaris van Sint-Anna, Cornelius Jansonius van Schoonhoven, wordt ontheven van zijn officie wegens zijn hoge leeftijd en ziekte. Vincentius Knibbe, geboren in Brussel in 1591, deed professie in Brussel op 22.1.1614, na studies in Leuven. Hij wordt naar Brugge gestuurd als procurator.

Nicolaus, donaat van Brugge, wordt naar Diest gestuurd.

\section{3 (Aanw. 593)}

\section{Overlijdens}

Cornelius Jansonius van Schoonhoven, profes van Geertruidenberg (Nederland), was meer dan 60 jaar kartuizer en gedurende 40 jaar vicaris in Sint-Anna waar hij overleed op 1.2.1623.

Daniel Tuer, profes van Sheen, overleed er als vicaris op 4.3.1623.

Richardus Baker, profes ibidem, overleed er op 10.11.1622.

Robertus Holden, convers ibidem sinds 1573, overleed er op 14.4.1623 (of, minder waarschijnlijk, 1622).

\section{Wijzigingen}

Thomas Jensema, profes van Lier, werd in Brugge sacrista benoemd door de visitator in 1622 . 
Gulielmus van Haecht, profes van Leuven in 1616, werd door de visitator tot procurator benoemd in Brugge in 1622.

\section{Ordinatio}

"We geven bovendien opdracht aan alle visitatoren van de provincies van de Orde ervoor te zorgen dat in alle huizen van hun provincies het decreet wordt gepubliceerd van onze H. Vader de Paus van 27.9.1622 om de oude gewoonten van de Orde te bewaren zowel bij het aanstellen van de priors als van de overige officieren." "

\section{4 (Aanw. 593)}

\section{Overlijdens}

Petrus Rolincx, profes van Brugge in 1569, was er sacrista en stierf er als antiquior in $1623 / 1624$.

Catharina Wautermans, ingetreden als converse tussen 1584 en 1592 , overleed er in $1623 / 1624$.

Wijzigingen

Geen.

\section{5 (Aanw. 593)}

Overlijdens

Geen.

\section{Wijzigingen}

Cornelius Rouberghere, profes van Diest, vraagt zelf naar Brugge te mogen gaan en wordt er sacrista.

\section{6 (Aanw. 593)}

\section{Overlijdens}

Melchior Charles, profes van Leuven, in 1596, gestorven als procurator van Sint- Anna op 3.8.1625.

Cornelia Mertens trad in als donate in 1607 en overleed aan de gevolgen van de pest (?) in 1625/1626.

\section{Wijzigingen}

Paulus vander Haeghen, profes van Diest, werd benoemd tot procurator van Sint-Anna in 1625 en wordt nu in deze functie bevestigd

3 Officieren zijn diegenen die in een kartuis een officium, een bediening bekleden Het zijn de prior, vicaris, procurator en sacrista. Soms ook de antiquior en coadjutor. 
door de visitator.

De communiteit van Sheen is zich in 1626 komen vestigen in Nieuwpoort. De volgende raad wordt haar gegeven: "Wij geven met de meeste nadruk opdracht aan de prior en de conventuelen dat ze helemaal niets ondernemen wat betreft een verandering van plaats en dat ze noch verkopen noch kopen zonder uitdrukkelijke toelating van de visitator."

\section{7 (CE 738)}

Overlijdens

Johannes Fennet, convers van Sheen, overleed op 22.11.1626.

\section{Wijzigingen}

Augustinus van Dorpe, profes van Herne, wordt verplaatst naar Brugge.

Fredericus Kogelkenius, profes van Herne, wordt uit Brugge naar Roermond verplaatst.

\section{Ordinationes}

Voor een beter onderhouden van paragraaf 4 van hoofdstuk 21 van het tweede deel van de statuten, verklaren wij dat zij die naar een ander huis gezonden worden en duidelijk van de kortste weg afwijken, aan de straf voorzien voor vluchtende religieuzen onderworpen zullen worden en dat zij die reisgeld ontvingen en het gebruiken voor andere doeleinden zonder uitdrukkelijke toestemming van de overste, aan de straf voorzien voor hen die onrechtmatig geld bezitten onderworpen zullen worden. De oversten moeten waken dat dit niet gebeurt en moeten de normaal voorziene rechtspraak toepassen.

\section{8 (CE 739)}

\section{Overlijdens}

Bertinus Oliver, profes van Sheen, was vicaris van Brugge en overleed op 12.10.1627 in Gent waar hij op doorreis was.

Georgius Eglionby, profes van Sheen in april 1597, stierf op 20.10.1627.

David Lewis, convers van hetzelfde convent vóór 1579, overleed op 26.9.1627.

Jacobs Olden, ingetreden als moniale in 1612, overleed in $1627 / 1628$ 


\section{Wijzigingen}

Joannes Hutton, profes van Sheen, was procurator in Mechelen van 1620 tot 1626 . Dan ging hij naar Leuven. Hij moet nu zijn communiteit vervoegen in Nieuwpoort.

Aan de prior van Sheen te Nieuwpoort wordt gevraagd ten vlugste de status van zijn huis mee te delen aan de visitator.

Jozef Scheldens, profes van Sint-Sofie te 's Hertogenbosch, door de visitator aangesteld als vicaris van Sint-Anna in 1627, wordt in deze functie bevestigd.

\section{9 (Aanw. 593)}

Overlijdens

Geen.

\section{Wijzigingen}

Henricus Bijl, geboren te Venlo en profes van Leuven in 1616, wordt in Sint-Anna benoemd, komende van Herne waar hij procurator was. Augustinus van Dorpe, profes van Herne, die in 1627 naar Brugge kwam, keert terug naar Herne.

\section{c. 1630 (CE 1503)}

\section{Overlijdens}

Johannes Baptista Daniels, profes van Leuven, was prior in Brugge van 1604 tot ca. 1608/1609. Overleed op 12.12.1629 in Leuven.

Maria Neytz, ingetreden als moniale omstreeks 1625, bezat toen nog een huis in Klemskerke.

Anna van Crombrugghe, dochter van Filips, burgemeester van Veurne, en van Helena Mestdagh, was nog novice bij haar overlijden.

\section{Wijzigingen}

Cornelis Rouberghere, profes van Diest, gaat van Brugge naar SintMartens-Bos. Hij had in 1625 gevraagd naar Brugge te mogen gaan, waar hij sacrista was.

Gisbertus Bijl, profes en sacrista van Sint-Martens-Bos wordt sacrista in Brugge, zoals hij gevraagd had.

Joannes Hutton verhuist op zijn verzoek van Sheen, zijn huis van professie, naar Sint-Martens-Bos.

\section{1 (Aanw. 593)}

Overlijdens

Cornelius Le Roux, profes en antiquior van Brugge, stierf er op 
9.4.1630.

Thomas Greene, profes en vicaris van Sheen, overleed er in $1630 / 1631$.

Joannes Sloyer, convers van hetzelfde huis, overleed in 1630/1631. In mijn lijsten heb ik die niet. Wel heb ik Joannes Floyde, convers en profes op 25.6.1630, overleden op 18.8.1636. Is dat dezelfde en dus een fout van de carta?

\section{Wijzigingen}

Nicolaus Hendrickx, alias Liranus, donaat van Lier, verbleef in Brugge en moet nu terugkeren naar Lier.

Egidius de Winte, convers van Brussel in 1618, gaat van Lier naar Brugge.

Judocus Gindertaler, profes van Brussel op 17.9.1617, die in Antwerpen cantor en later procurator was, gaat nu naar Brugge.

\section{2 (Aanw.593)}

\section{Overlijdens}

Franciscus, convers van Brugge voor 1614, overleed er in 1631/1632. Catharina De Clercq, ingetreden als moniale in mei 1604, werd priorin in 1615 en bleef het tot aan haar dood op 26.2.1632.

\section{Wijzigingen}

Franciscus van der Meulen, die prior was in Brugge, gaat naar Lier, zijn huis van professie, als vicaris. Hij wordt opgevolgd door Carolus vander Guchte, profes van Sint-Martens-Bos waar hij dan vicaris was. Catharina Vrombaut, die op 26.2.1632 priorin verkozen was, wordt in deze functie bevestigd.

\section{3 (CE 2517)}

\section{Overlijdens}

Jozef Scheldens was profes van Sint-Sofie in 's Hertogenbosch. Hij was vicaris van de monialen sinds 1627 en overleed er op 15.9.1632.

\section{Wijzigingen}

Bruno Emtinck, profes van Sint-Martens-Bos gaat van deze kartuis naar Sint-Anna als coadjutor.

Simon de Bode, profes van Leuven, wordt vicaris van Sint-Anna in 1632. Hij wordt nu bevestigd in deze functie die hij zal uitoefenen tot kort voor zijn dood (c. 1658).

Henricus Bijl, profes van Leuven, keert naar zijn huis van professie 
terug, na sinds 1629 coadjutor te zijn geweest in Sint-Anna.

\section{c. 1634 (CE 2517)}

\section{Overlijdens}

Hoewel Corneel Moens geen kartuizer was, wordt zijn naam speciaal vermeld omdat hij provendarius domus mon. Brugis was d.w.z. degene die zorgde voor de boodschappen. Hij overleed op 27.3.1634. Was hij werkzaam voor de monialen of voor de monniken? De vermelding laat niet toe te zeggen voor wie hij werkte.

Joanna Sutiers, ingetreden als converse in 1598. Een van haar voogden was Passchier Sutiers, beheerder van de Armentafel van Brugge. Ze had een zuster, Maria, die koormoniale was van Sint-Anna (159014.3.1645).

\section{Wijzigingen}

Joannes Oppers, profes van Lier, in Brugge aangekomen in 1631, gaat naar Leuven.

Joannes Hutton, profes van Sheen, sinds c. 1630 in Sint-Martens-Bos, keert terug naar Sheen.

Michael de Simpol, profes ca 1627 in Sint-Martens-Bos, gaat op zijn verzoek van Sheen naar Antwerpen, waar hij slechts zeer korte tijd verbleef.

\section{c. 1635 (CE 2517)}

Overlijdens

Elisabeth van Gavere trad binnen als moniale omstreeks 1561. Was onderpriorin van 1588 tot 1603 . Ze ondertekende mede de rekeningen zonder vermelding van functie van 1605 tot 1633 . Ze overleed op 13.12.1634.

\section{Wijzigingen}

Geen.

\section{c. 1636 (CE 2514)}

\section{Overlijdens}

Geen.

Wijzigingen

Carolus van der Guchte, profes van Sint-Martens-Bos, overleed als prior van Brugge in 1634. Hij werd vervangen door Joannes Pipenpoy, profes van Brussel, die rector was tot aan de c. 1636, die hem benoemt tot prior. 
Op de eerste blz. staat: "Bestemd voor het huis der monialen te Brugge."

\section{c. 1637 (CE 2513)}

\section{Overlijdens}

Robertus Dalton, vermeld als vicaris van Sheen in 1626 , overleed op 26.11.1636.

Bartholomeus Kellam, convers van Sheen voor 1626, overleed op 15.3.1637.

Abraham Ellis, convers van Sheen voor 1608, overleed als hospes in El Paular (Spanje) in 1637. Hij wordt ook vermeld in de c. 1638. Barbara de Brune als converse ingetreden in het begin van de $17 \mathrm{de}$ eeuw, overleed op 10.12.1636.

\section{Wijzigingen}

Bruno Clement, profes van Diest, gaat van Brussel naar Brugge. Joannes Hutton, profes van Sheen, gaat van Sheen naar Leuven.

\section{Ordinatio}

Niemand mag tot de staat van convers worden toegelaten, tenzij hij voordien gedurende vijf jaar de staat van donaat had.

\section{8 (CE 966)}

\section{Overlijdens}

De carta schrijft: "D. Arnoldus professus domus Lyrae alias vicarius domus monialium Brugis". Ik heb deze monnik aanvankelijk aangezien als Andreas Gaethoven die stierf op 6.11.1637 en profes was van Lier. Maar deze is echter nooit vicaris geweest van de Brugse monialen. Het gaat hier om een vergissing van de carta. Deze Arnoldus die wel bij de zusters verbleef is eigenlijk Gerardus, alias Arnoldus, Eligii Raddelet. Hij was er van 1616 tot 1621 en was hulpvicaris van Cornelius Jansonius van Schoonhoven, die wegens zijn blindheid een helper nodig had op het eind van zijn leven.

Paulus vander Haeghen, profes van Diest, overleed als procurator van Sint-Anna.

\section{c. 1639 (CE 2088)}

\section{Overlijdens}

Antonius Langworth deed professie in Sheen voor 1626. Hij overleed op 9.4.1639.

Catharina Vrombaut, ingetreden als moniale in april 1603, was celleraria van $1617 / 1618$ tot 1632 . Ze werd priorin op 26.2.1632 en over- 
leed in deze functie vermoedelijk even voor 1.10.1638.

Francisca Lambrechts trad in als converse in 1610 . Ze was portierster en overleed op 20.8.1638.

\section{Wijzigingen}

Gisbertus Bijl, profes van Sint-Martens-Bos, gaat van Brugge, waar hij sacrista was, terug naar zijn huis van professie.

\section{0 (CE 965)}

\section{Overlijdens}

Franciscus vander Meulen, oud-prior van Brugge, stierf in Lier op 16.5.1639.

\section{Wijzigingen}

Hugo Gelos, profes van Diest, gaat terug naar Diest komende van Brugge.

Antonius du Lieu, profes van Sint-Martens-Bos, wordt van Diest verplaatst naar Brugge. In Sheen: "De visitator moet met zorg de klachten onderzoeken die gedaan zijn tegen Joannes Hutton. Indien hij hem schuldig bevindt, moet hij hem straffen door hem in de kerker te zetten met beperking van voedsel, en anders op de wijze die zijn geval vereist."

\section{c. 1641 (CE 2494) \\ Overlijdens}

Geen.

\section{Wijzigingen}

Joannes Hutton, profes van Sheen, gaat van Sheen naar Brugge.

\section{c. 1644 (CE 1504)}

\section{Overlijdens}

Thomas Hallowes, profes van Sheen, prior van dat huis, overleed in deze functie op 3.1.1644.

Clara van Hondeghem trad binnen in 1620 als moniale en overleed op 28.2.1643.

\section{Wijzigingen}

Antonius Naylor, profes van Sheen, begaf zich van dat huis als hospes naar Brugge.

Antonius du Lieu, profes van Sint-Martens-Bos, ging van dat huis 
naar Brugge als hospes.

Jacobus Cambrelin gaat van Brugge naar Sheen. We hebben geen andere gegevens over deze monnik.

Joannes Duckett, zoon van de martelaar Jacobus Duckett, deed als seculier priester professie op 15.7.1629 en werd, reeds vicaris zijnde, tot prior verkozen na de dood van Thomas Hallowes.

\section{c. 1645 (CE 2410)}

\section{Overlijdens}

Joanna Toris, ingetreden als donate in 1636.

Wijzigingen

Geen.

c. 1649 (CE 1827)

Overlijdens

Geen

Wijzigingen

Geen.

1650 (onvolledige carta) en 1651 (CE 732)

Overlijdens

Geen.

Wijzigingen

Geen.

\section{c. 1652 (CE 2320)}

Overlijdens

Joannes Hutton, prior van Sheen sinds 1647, overleed op 23.10.1651 Volgens de carta: "prior domus Angelorum Neoporti"!

Catharina Carron trad in als moniale in 1603. Van 1633 tot 1647 ondertekende ze mede de rekeningen zonder vermelding van functie. Ze stierf op 19.8.1651.

Elisabeth Foreest trad in als donate in 1599.

\section{Wijzigingen}

Thomas Gerard, profes van Sheen, werd door Reverendus Pater in 1651 , na het overlijden van Joannes Hutton, aangesteld tot prior. Hij wordt nu in deze functie bevestigd. 


\section{c. 1653 (CE 2481) \\ Overlijdens}

Edmundus Ireland was procurator van het Engels College te Douai van 1641 tot 1647 . Hij deed professie in Sheen in november 1649. Hij overleed er op 1.4.1652.

Antonia Aerts trad in als moniale in 1602. Ze ondertekende de rekeningen mee van 1628 tot 1652 zonder vermelding van functie.

\section{Wijzigingen}

Geen.

Op het einde van de carta staat: "Deze moet gezonden worden naar Sint-Martens-Bos en daarna naar Gent." Een andere hand schreef erbij: "Moet naar Nieuwpoort gezonden worden."

\section{c. 1654 (CE 2481)}

Overlijdens

Andreas vander Meeren, convers van Brussel in 1613, overleed als hospes van Brugge op 12.10.1653.

Gulielmus Skinner, donaat van Sheen sinds 1635 .

Catharina Wynckelman, converse sinds 1606/1607.

\section{Wijzigingen}

In Brugge werd in 1653 door Reverendus Pater tot prior benoemd, in vervanging van Joannes Pipenpoy die prior werd in Brussel, zijn huis van professie, Gregorius Raeymaeckers, profes van Leuven in 1626.

Georgius Transam studeerde aan het Engels College te Douai waar hij ook professor was. Hij trad binnen in Sheen in 1637. Hij was er vicaris van 1647 tot 1654 , jaar waarin hij tot prior van Sheen werd benoemd.

\section{5 (OKA 338)}

Overlijdens

Maria Valentijn, ingetreden als donate in $1604 / 1605$, overleed in 1655.

Wijzigingen

Geen. 


\section{9 (OKA 338)}

Overlijdens

Eduardus Fettiplace, profes van Sheen, na procurator geweest te zijn van het Engels College te Douai, in november 1649. Gestorven op 31.3.1659.

Antonius Naylor, profes van Sheen, verbleef in 1644-1645 in Brugge en overleed in Nieuwpoort op 9.4.1659.

Catharina Tilly, ingetreden als moniale in 1643. Dochter van Frans Tilly. Professie in 1644. Gegoede familie. Overleden op 25.7.1658.

Catharina Bruneels, ingetreden als converse in 1635 en overleden op 24.6.1658.

Maria Tillemans, ingetreden als donate in 1639 en overleden in 1659 .

\section{Wijzigingen}

Anthelmus Queremans, donaat van Brugge, keert uit Herne terug naar Brugge.

Hugo van Gessel wordt ontheven van zijn prioraat van Sint-MartensBos om prior te worden in Brugge waar hij Michael Coolen opvolgt. Hij was profes van Sint-Martens-Bos op 3.8.1637, waar hij ook procurator was.

Robertus Clarke, profes van Sheen, komt van Brugge terug in zijn huis van professie.

\section{0 (OKA 338)}

\section{Overlijdens}

Clara Verlinden, als donate ingetreden tussen 1621 en 1627, overleden in 1660 .

\section{Wijzigingen}

Nicolaus Marchand, donaat van Sint-Martens-Bos, gaat van Brugge naar Scheut.

"We geven opdracht aan de visitatoren de grenzen van de wandelingen van het klooster van Brugge op een behoorlijke wijze, conform met de reguliere discipline, vast te leggen." ${ }^{4}$

4 De monniken maken wekelijks een wandeling in de omgeving van het klooster. Daarvoor mogen ze evenwel niet buiten bepaalde limieten gaan. Deze grenzen worden vastgelegd in een officieel document. 


\section{1 (OKA 338)}

Overlijdens

Jozef Le Comte, profes van Brugge omstreeks 1648, was sacrista en werd in 1658 vicaris. Overleden op 22.9.1660.

Maria Tollenaere, ingetreden als moniale in 1613, toen haar moeder reeds weduwe was van Antoon Tollenaere. Deed professie in 1615 en overleed in 1661. Zeer gegoede familie.

\section{Wijzigingen}

Gulielmus van Haecht, procurator van Brugge, keert terug naar Leuven, zijn huis van professie, waar hij procurator zal zijn.

Nicolaus Brouckman, profes van Brugge, wordt er procurator.

Andreas Jacobs, profes van Sint-Martens-Bos en procurator, wordt vicaris in Brugge.

\section{2 (CE 37)}

\section{Overlijdens}

Hugo van Gessel, profes van Sint-Martens-Bos op 3.8.1637, overleed als prior van Brugge op 23.8.1661.

Maria van Munnekereede, ingetreden als moniale in 1612, overleed midden 1661 .

Elisabeth Forchout, ingetreden als converse in 1638, overleed in $1661 / 1662$.

Anna de Boosere, ingetreden als converse in 1639, overleed in $1661 / 1662$ na 3 jaar ziekte. Ze was verantwoordelijk voor de apotheek.

\section{Wijzigingen}

Andreas Jacobs, profes van Sint-Martens-Bos, werd vicaris benoemd te Brugge op 20.6.1661, maar reeds enkele weken later werd hij er prior.

Anthelmus vander Plancken, profes van Sint-Martens-Bos omstreeks 1655 , werd vicaris in Brugge als opvolger van Andreas Jacobs.

Benedictus Vrancx, profes van Sint-Martens-Bos, vicaris in Sheen, keert terug naar zijn huis van professie.

Petrus Bilcliffe, profes van Sheen op 4.1.1661, wordt er vicaris.

\section{c. 1664 (CE 1827) onvolledig}

\section{Overlijdens}

Cornelia de Coninck, vermoedelijk uit Duinkerke afkomstig, trad als moniale binnen in 1610. Ze overleed op 4.7.1663. 


\section{Wijzigingen}

Andreas Jacobs, profes van Sint-Martens-Bos, krijgt misericordia (d.i. ontslag) als prior van Brugge op zijn dringend verzoek en keert terug naar zijn huis van professie. Hij wordt vervangen door Josephus d' Outelair, profes van Brussel in 1635, die in Antwerpen was op dat moment.

\section{c. 1665 (CE 1220) \\ Overlijdens \\ Geen.}

\section{Wijzigingen}

Antonius du Lieu, vicaris van Brugge, keert terug naar Sint-MartensBos, zijn huis van professie, en wordt er eveneens vicaris.

Bruno Clement, profes van Diest, werd in 1664 sacrista in Brugge en wordt nu in deze functie bevestigd.

Gregorius Macquet gaat van Sint-Martens-Bos, zijn huis van professie, naar Brugge als vicaris.

Joannes Cool, profes van Brugge, verlaat dit huis voor Diest.

\section{9 (CE 781)}

\section{Overlijdens}

Magdalena Campinck, geboren in 1600 of 1601, ingetreden als donate in 1626 , overleed op 15.2.1669.

\section{Wijzigingen}

Jozef d' Outelair, profes van Brussel op 10.3.1635, wordt verplaatst als prior van Brugge naar Antwerpen.

Hugo van der Straeten, profes en vicaris van Gent, wordt prior in Brugge.

Bernard d' Outelair, profes van Chercq, was sacrista van Brugge van 1640 tot 1643 , werd er dan vicaris tot 1658 , en werd na een verblijf in Antwerpen, weer vicaris in Brugge in 1668.

Antonius du Lieu (in deze carta verkeerdelijk vermeld als Anthelmus) was procurator in Sint-Martens-Bos, toen hij benoemd werd tot procurator van Sint-Anna. Hij verving er Franciscus Bodart, profes van Lier, die procurator was van Sint-Anna van 1666 tot 21.6.1669. Dan werd hij procurator in Sint-Martens-Bos.

Petrus Bilcliffe werd in 1668 tot prior verkozen van Sheen en wordt nu in dit ambt bevestigd. 


\section{0 (CE 967)}

\section{Overlijdens}

Petrus Constable, profes van Sheen Anglorum, overleed er als procurator op 13.3.1670.

Petronilla vande Walle, geboren in 1589 , ingetreden als moniale in 1617. Overleden op 25.2.1670.

\section{Wijzigingen}

Petrus Langhedul, profes van Gent, in 1669 met goedkeuring van de visitator als vicaris aangesteld in Brugge, wordt bevestigd in deze functie.

Paulus van Hoorne, profes van Sint-Martens-Bos in 1668, wordt overgeplaatst naar Brugge.

\section{3 (OKA 338)}

\section{Overlijdens}

Geen.

\section{Wijzigingen}

Anthelmus Cottel, profes van Lier, verkozen door de Brugse monniken tot prior in 1672 , wordt bevestigd in deze functie.

Paulus van Hoorne, profes van Sint-Martens-Bos, gaat van Herne naar Sheen waar hij vicaris wordt.

Jacobus Bertwisle, profes van Sheen, gaat van zijn klooster van professie naar Brugge.

\section{4 (OKA 338)}

\section{Overlijdens}

Maria de Tollenaere, priorin sinds 30.8.1667, overleed op 29.1.1674. Ze werd geboren eind 1625 uit een zeer gegoede familie. Ze trad binnen in 1649. Was novicemeesteres van 1657 tot 1667.

\section{Wijzigingen}

Christianus Weyts, profes van Brussel in 1671, wordt procurator in Sint-Anna.

Antonius du Lieu, profes van Sint-Martens-Bos, was procurator van Sint-Anna en wordt er nu coadjutor.

Georgius Millian, profes van Brussel, coadjutor van Sint-Anna, wordt hospes in Herne. 


\section{5 (OKA 338)}

Overlijdens

Christianus Weyts, profes van Brussel, overleed als procurator van Sint-Anna op 15.6.1674.

Maria de Wyen, geboren in 1608, ingetreden als moniale begin 1629 , overleed op 30.11 of 13.12 .1674 .

Anna Berblock, geboren omstreeks 1590, trad in als donate in 1612 en overleed op 1.6.1674.

\section{Wijzigingen}

Justus de Paepe, profes van Lier, werd in 1674 vicaris benoemd van Sheen door de visitator en wordt nu in dit ambt bevestigd.

Constant Magnus, profes van Gent, werd in 1674 benoemd tot procurator van Sint-Anna door de visitator en wordt nu in deze functie bevestigd.

\section{7 (OKA 338)}

Overlijdens

Jozef d' Outelair, profes van Brussel, oud- prior van Brugge, overleed als prior van Antwerpen op 21.3.1677.

Christina Brouckman, geboren in 1639 , ingetreden als moniale in 1660 , deed professie in 1661 en overleed in mei of juni 1676 . Ze is waarschijnlijk de zuster van zuster Aldegondis Brouckman en verwant met Nicolaas Brouckman.

Judoca Verhelle, geboren in 1604, ingetreden als donate in 1632, overleed op 6.7.1676.

\section{Wijzigingen}

Melchior Pletincx, profes van Herne, verlaat Brugge, waar hij vicaris was, om prior te worden in Herne.

Nicolaas Brouckman, profes en procurator van Brugge, wordt er prior in opvolging van Anthelmus Cottel.

Jacobus Bertwisle keert terug vanuit Lier naar Sheen, zijn huis van professie.

Justus de Paepe (in deze carta verkeerdelijk Jozef geheten) keert terug vanuit Sheen naar Lier, zijn huis van professie.

Henricus Petit, prior van Herne, wordt benoemd tot vicaris van de monialen 


\section{9 (OKA 338)}

\section{Overlijdens}

Thomas Owst, profes van Sheen, overleed als procurator op 15.1.1679.

Petrus Brigham, profes van datzelfde huis, overleed in Brugge als hospes op 30.1.1679.

Anna Huerblock, geboren in 1614, ingetreden als moniale in 1633, overleed op 16.1.1679. Ze was een natuurlijk kind en erkend door Michiel Wouters.

\section{Wijzigingen}

Bavo van Hulthem, profes van Gent, wordt verplaatst van Brugge naar Leuven.

Paulus van Hoorne, die in Brugge in de kerker zit, keert terug naar zijn huis van professie, Sint-Martens-Bos, waar hij verder zijn straf moet uitzitten in de kerker. $^{5}$

Bruno d' Avila, profes van Lier, hospes in Brugge, moet zijn kwade tong bedwingen waarmee hij niet ophoudt de Orde te belasteren en de jonge religieuzen aanzet tot misprijzen van de statuten en de oversten. Die jongeren moeten zijn schadelijke praatjes vermijden.

Egidius vanden Berghe keert uit Brugge terug naar Antwerpen, zijn huis van donatie.

Franciscus de Rycke, profes van Sint-Martens-Bos, keert terug van Brugge naar zijn huis van professie.

Anthelmus de Veltere, profes van Brugge, keert er terug vanuit Brussel.

Jozef vander Hulst, donaat van Brugge, keert er terug vanuit Antwerpen.

\section{1 (OKA 338)}

\section{Overlijdens}

Petrus Herts, donaat van Herne in 1672, overleed als hospes in Brugge. Maria Wouters, geboren in 1604, ingetreden als moniale in 1623 , professie in 1625, uit een gegoede familie, overleed op 16.2.1681.

5 Als een monnik een belangrijke overtreding had gepleegd, werd hem soms opgelegd in de kerker te verblijven. Dit is een cel die iets kleiner is dan een normale cel, maar die alleen kleine, hooggeplaatste vensters heeft. Tegenwoordig bestaat die kerker niet meer, omdat voor zwaardere vergrijpen de religieuzen geëxclaustreerd kunnen worden d.i. tijdelijk buiten hun klooster verblijven. De exclaustratie is niet noodzakelijk het gevolg van een misstap. Het kan gaan om gezondheidsredenen of andere omstandigheden zoals studie. 
Wijzigingen

Jan-Baptist Verstrepen, profes van Herne, wordt overgeplaatst van Brugge naar Antwerpen.

Willibrord Buckenberg, profes en procurator van Diest, wordt vicaris in Brugge.

Bonaventura Rotsaert, profes van Brugge, keert terug naar Brugge van uit Brussel.

Gregorius Sutrix, profes van Lier, door de visitator aangesteld als procurator van Sheen, wordt in deze functie bevestigd.

\section{2 (OKA 338)}

Overlijdens

Joannes Pipenpoy, profes van Brussel, oud-prior van Brugge, overleed op 9.5.1681.

Joannes Barnesly, profes van Sheen, stierf er op 10.10.1680.

Amandus Denys, donaat van Sint-Anna, overleed als hospes in SintMartens-Bos.

Norbertus Symons, donaat van Brugge.

Magdalena Loones, converse van Sint-Anna, geboren in 1606, ingetreden in 1634, overleed op 17.3.1682.

\section{Wijzigingen}

Octavianus vanden Bogaerde, profes van Brugge, wordt overgeplaatst van Brugge naar Lier.

Hieronymus Hoppenbrouwer, profes van Antwerpen, gaat vanuit Lier naar Sint-Anna als coadjutor.

Benedictus Germees, profes van Sint-Martens-Bos, wordt overgeplaatst naar Brugge vanuit zijn huis van professie.

Barnabas de Bergas, profes van Leuven, gaat van daaruit naar Brugge.

Dionysius van Heumel, profes van Brussel, gaat van Sint-Anna naar Brugge waar hij procurator wordt.

\section{c. 1689 (CE 2480)}

Overlijdens

Elisabeth vander Leene, geboren omstreeks 1628, trad binnen als moniale in 1648 . Ze was cantor gedurende 25 jaar en overleed op 13 of 14.3.1689. 


\section{Wijzigingen}

Hiëronymus vanden Kerckhove, profes en procurator van Gent, wordt benoemd tot prior van Brugge.

Joannes-Baptista Wauwermans, profes van Antwerpen, verlaat Brugge om vicaris te worden van Sint-Martens-Bos.

Hugo Pirot keert terug uit Brugge naar Gent, zijn huis van professie.

\section{c. 1690 (CE 2480)}

\section{Overlijdens}

Petrus Aerts, profes van Diest, stierf als hospes van Brugge op 20.8.1689.

\section{Wijzigingen}

\section{Geen.}

\section{c. 1693 (CE 2088) \\ Overlijdens}

Petrus Bilcliffe, profes van Sheen op 4.1.1661, was reeds vicaris in 1662 en werd prior in 1668. Hij overleed in deze functie op 13.2.1693. Hij was gekend als auteur.

Joannes-Antonius Garnet overleed als profes en vicaris van Sheen op 14.2.1693.

Christianus Hazzard, donaat van Sheen, stierf er op 27.2.1693.

(Dus drie overlijdens in de maand februari 1693 in dit kleine convent!)

Thomas Whale, profes en eertijds vicaris van Sheen, overleed er op 5.7.1692.

Josepha Bierewaert, geboren in 1645, trad binnen als moniale in 1670. Ze was celleraria van 1685 tot 1692 . Ze was ook novicemeesteres en stierf op 30.1.1693.

Catharina Rosseels, geboren in 1626, trad binnen als moniale in 1660. Ze ondertekende zonder vermelding van functie de rekeningen van 1690 tot 1692 . Ze overleed op 29.12.1692.

\section{Wijzigingen}

Anthelmus de Veltere, profes van Brugge, werd tot prior van zijn kartuize verkozen in 1692 en nu bevestigd. Zijn voorganger, Constantinus Magnus, werd prior verkozen in Gent.

Thomas Thurold, profes van Sheen, werd er in 1692 tot prior verkozen en nu bevestigd.

Hugo Pirot, profes van Gent, werd in 1692 aangesteld als vicaris van 
Sheen en nu bevestigd.

\section{c. 1694 (CE 1874) \\ Overlijdens}

Henricus Petit, profes van Herne, was vicaris van Sint-Anna van 1677 tot 1680 . Hij overleed als prior van Lier.

Robertus Willasie, profes van Sheen, stierf er op 14.12.1693.

Theresia Hostens, geboren in 1666, trad binnen in 1686 en overleed op 23 of 24.11 .1693 .

Ludwina Strobbe, geboren in 1641, trad binnen als converse in 1662. Ze stierf op 27.5.1693.

\section{Wijzigingen}

Henricus Raeymaeckers, profes van Brussel in 1674, was tot prior verkozen van Herne in 1692. Door deze carta wordt hem misericordia verleend en gaat hij als vicaris naar Brugge.

Josephus van Hecke, profes van Herne, gaat van Herne naar Brugge. Josephus van Thienen, profes van Brussel in 1678, keert uit Brugge terug naar zijn huis van professie.

Bernardus Ketelaere, profes van Antwerpen, hospes in Brugge, verlaat deze kartuize voor Sint-Martens-Bos.

Jacobus Boele, profes van Sint-Martens-Bos in 1684, wordt verplaatst naar Brugge.

Franciscus de Rycke, profes van Brugge in 1673, was hospes in Sheen sinds ca 1691 en wordt nu naar Herne overgeplaatst.

Godelieve Le Maire, die tot priorin verkozen was einde 1693, wordt in deze functie bevestigd.

\section{c. 1695 (CE 2516)}

Overlijdens

Geen.

\section{Wijzigingen}

Joannes-Baptista van Hoorebeke, profes en vicaris van Gent, werd in 1694 aangesteld als prior van Sheen en nu bevestigd in deze functie.

\section{c. 1696 (CE 2516)}

Overlijdens

Joannes-Baptista Wouters, profes van Brugge in 1675, sacrista sinds 1689 , overleed er in deze functie. 


\section{Wijzigingen}

De prior van Sheen, Joannes-Baptista van Hoorebeke, krijgt op zijn dringend verzoek misericordia en gaat als vicaris naar Leuven.

Octavianus van den Bogaerde, profes van Brugge, werd in 1695 aangesteld als vicaris van Sheen en nu bevestigd.

In deze carta volgt hierop een tekst die wijst op de moeilijkheden die de Orde had met deze kartuize.

"Dit huis echter, dat tot nu toe zeer lastig was voor de Orde wegens zijn verwaarlozing van de regel en verschillende overtochten naar Engeland om aalmoezen, maar vooral wegens zijn hardnekkige wil steeds een Engelse prior te hebben, hoewel het slechts vijf monniken heeft, waarvan twee priester, en die onlangs op Reverendus Pater druk hebben uitgeoefend om de ontheffing te vragen van de prior die uit zijn midden voortkwam, na hem een proces te hebben aangedaan wegens vele fouten tegen de regel, dit huis dus steunen we deze keer nog en laten het toe een prior te kiezen. Maar indien de monniken zich voor het overige niet beter dan voorheen gedragen volgens de voorschriften van de statuten, beslissen en bevelen we dat dit huis van de Orde wordt afgescheiden, opdat het voortaan voor ons geen voorbeeld van inobservantie noch een schandaal weze."

Bruno Simons, profes en prior van Lier, wordt ontheven als zodanig en wordt vicaris van Sint-Anna in de plaats van Hiëronymus van Nijverseel, die naar Lier gaat eveneens als vicaris.

\section{c. 1697 (CE 2516)}

Overlijdens

Geen.

\section{Wijzigingen}

Gulielmus Hall, profes van Sheen in 1693, werd in 1696 prior benoemd in Sheen en nu bevestigd

\section{c. 1698 (CE 2516) \\ Overlijdens}

Godelieve Le Maire, priorin van 10.12.1693 tot 23.04.1697, overleed op 19 mei van datzelfde jaar.

Barbara Le Fer, geboren in 1622, ingetreden als converse in 1649 , was de verantwoordelijke van de kloosterapotheek. Ze stierf op 15.8.1697. 


\section{Wijzigingen}

Josephus Keingiart, profes van Gent, wordt benoemd tot coadjutor van Sint-Anna in vervanging van Fredericus Fredrickx, profes van Brussel, die van Sint-Anna naar Herne gaat.

Gulielmus vander Looven, profes van Herne, werd in 1697 tot vicaris van Sheen benoemd en nu bevestigd.

Dorothea Willems, tot priorin verkozen in 1697 , wordt bevestigd in deze functie.

Voor het huis van Sheen voegt de carta het volgende bij: "Wij verbieden echter in dat huis voortaan nog novicen op te nemen tot wanneer het naar het oordeel van de visitatoren in een beter conditie verkeert zowel op geestelijk als op tijdelijk vlak."

\section{0 (CE 782)}

\section{Overlijdens}

Geen.

\section{Wijzigingen}

Anthelmus de Veltere, profes van Brugge in 1661, vraagt ontheven te worden van zijn functie als prior. Hij wordt vervangen door Hugo Pirot, profes van Gent, die dan vicaris was van Sheen.

Egidius vanden Berghe, donaat van Antwerpen, keert terug vanuit Brugge naar Antwerpen.

Thomas Thurold, profes van Sheen op 22.7.1686, keert terug van Luik naar zijn huis van professie.

Georgius Hunter werd door de conventuelen van zijn huis Sheen tot hun prior verkozen in 1699 en door Révérend Père bevestigd. "We laten toe dat novicen aanvaard worden in dat huis (Sheen), na voor elk afzonderlijk een onderzoek en de goedkeuring van de visitatoren. Die mogen slechts de toelating geven voor zover hun aantal past in de mogelijkheden van dit huis, zodat ze daar kunnen onderhouden worden zonder te moeten zoeken naar ongepaste oefeningen die door de statuten verboden zijn, bv. dat iemand onder welk voorwendsel ook voortaan naar Engeland moet gaan om aalmoezen te schooien.

\section{c. 1701 (CE 1749) \\ Overlijdens}

Geen. 


\section{Wijzigingen}

Embertus Hellincx, profes en vicaris van Antwerpen, wordt tot procurator van Sint-Anna aangesteld, en Franciscus Tou die er procurator was wordt er vicaris.

De oud-vicaris Bruno Simons, sinds 1696 in functie, wordt overgeplaatst naar Gent ook als vicaris.

Josephus Keingiart, sinds 1698 coadjutor van Sint-Anna, keert terug naar Gent, zijn huis van professie.

\section{c. 1702 (CE 2479) \\ Overlijdens}

Constantinus Magnus, die procurator en vicaris was in Sint-Anna van 1680 tot 1691 en prior van Brugge in 1691 , overleed als prior van Gent op 5.10.1701.

Joannes Baes, donaat van Brugge, stierf vorig jaar, maar werd vergeten in de vorige carta.

Jacoba de Grutere, geboren omstreeks 1626, trad binnen als moniale in 1643 . Ze ondertekende mede de rekeningen van 1667 tot 1673 zonder vermelding van functie. Op 17.2.1674 werd ze priorin en bleef het tot 4.12.1693. Van 1694 tot 1698 ondertekent ze opnieuw de rekeningen zonder vermelding van functie. Ze stierf op 16.4.1701.

Maria de Villegas, geboren in 1630, trad binnen als moniale in 1648 . In 1689/1690 ondertekende ze mede de rekeningen zonder vermelding van functie. Van 1691 tot 1694 doet ze het als onderpriorin. Ze overleed op 2.8.1701.

Livina van Heylen trad binnen als moniale in 1670 en overleed op 12.12.1701.

Algegondis Brouckman, geboren in 1633, trad in als converse in 1655. Ze was portierster en overleed op 27.1.1702. Ze was zeer waarschijnlijk de zus van Christina Brouckman, ingetreden als moniale in 1660 .

\section{Wijzigingen}

Joannes-Baptista van Hoorebeke verlaat als prior Sint-Martens-Bos om prior te worden in Brugge en Hugo Pirot, prior van Brugge, vervangt hem in Sint-Martens-Bos.

Josephus van Spiers verlaat Brugge om vicaris te worden in Antwerpen, zijn huis van professie. 


\section{4 (CE 763)}

Overlijdens

Anthelmus Verfaillie, donaat Brugge voor 1710 , was procurator in Brugge tussen 1716 en 1720. Hij overleed op 24.5.1723.

Constantia du Persijn, ingetreden als moniale in 1681 . Ze was celleraria en novicemeesteres. Ze overleed als suppriorin op 25.7.1723.

\section{Wijzigingen}

Bruno de Cocq, profes van Gent omstreeks 1696, procurator van Sint-Anna tot 1722. Hij werd verkozen door de monniken van Gent tot prior in juni 1723 en wordt bevestigd in dit ambt.

Hugo Hoebens, profes van Gent, was procurator van Sint-Anna in 1723 en werd er dan als vicaris aangeduid en nu bevestigd in dit ambt.

Benedictus Wicart, profes van Brussel op 29.6.1709, werd in 1623 procurator benoemd in Sint-Anna door de visitator en nu in deze functie bevestigd.

\section{c. 1725 (CE 1932)}

Overlijdens

Henricus Swinnen, profes en prior van Diest, was van 1706 tot $1716 / 1717$ prior van Brugge.

\section{Wijzigingen}

Geen.

\section{c. 1726 (CE 2478)}

Overlijdens

Geen.

Wijzigingen

Geen.

\section{c. 1727 (CE 2478)}

\section{Overlijdens}

Ananias van Solten, profes van Valenciennes, is gestorven als hospes van Brussel. Hij was van 1709 tot 1711 vicaris van Sint-Anna.

Franciscus Thompson, profes van Sheen in 1711, stierf als vicaris van Sheen op 73.1727 . Hij is ook gekend als auteur.

Francisca Braeckelman, geboren in 1659, ingetreden als moniale in 1682, was celleraria van 1693 tot 1697 en van 1700 tot 1709 . Ze was 
onderpriorin van 1710 tot 1719 . Ze overleed, blind geworden in 1720, op 29.7.1726.

\section{Wijzigingen}

Jacobus Peeters, profes van Lier, was vicaris van Brugge sinds 1720 . Hij wordt nu verplaatst naar Luik.

Antonius Vivignies, profes van Luik, gaat van Luik naar Brugge om hem er als vicaris te vervangen.

\section{c. 1728 (CE 2478)}

\section{Overlijdens}

Philippus Joly, profes van Antwerpen, werd prior van Brugge in 1718 en overleed er in deze functie op 23.10.1727.

Georgius (hier verkeerd vermeld als Gregorius) Hunter, profes van Sheen in 1694, prior van 1700 tot 1715 , overleed er op 31.12.1727. Hugo de Clercq, profes van Brugge, vóór 1698, overleed als hospes van Lier, nog steeds diaken zijnde.

\section{Wijzigingen}

Antonius Vivignies, die vicaris was in Brugge, werd er in 1727 tot prior verkozen en nu bevestigd.

Joannes Geerts, profes van Lier ca. 1695, gaat op zijn verzoek van Brugge naar Gent.

Hugo Hoebens, vicaris van Sint-Anna sinds 1723 , gaat nu als vicaris naar Leuven.

\section{c. 1729 (CE 2495)}

Overlijdens

Columbanus Townley, was profes van Bourgfontaine (Frankrijk) in 1700. Hij was procurator van Sheen van 1705 tot 1708 en prior van 1718 tot 1722. Hij overleed er als hospes op 17.1.1729.

\section{Wijzigingen}

Geen.

Een nota op het einde van de carta zegt: "Van Brugge moet deze carta naar Nieuwpoort gestuurd worden en vandaar terug naar Brugge bij de monialen." 


\section{c. 1730 (CE 2515)}

Overlijdens

Josephus Betts, die weduwnaar geworden, in 1710 intrad in Sheen, waar hij prior was van 18.6.1722 tot aan zijn dood op 31.10.1729. Is ook vermeld als auteur.

Andreas van Langenhove, profes van Brussel in 1680, was prior in Brugge van 1716 tot 1718. Hij stierf te Brussel op 22.9.1719.

\section{Wijzigingen}

Bernardus Garemyn, profes van Gent, werd, toen hij vicaris van Antwerpen was, tot prior van Brugge benoemd in 1729 en door deze carta in deze functie bevestigd. Hij verving er Bruno Hermans, profes van Lier, die ook in 1729 benoemd werd tot prior van Antwerpen. Carolus Lee, profes en procurator van Sheen, werd in 1729 benoemd tot prior van Sheen en nu in deze functie bevestigd.

\section{c. 1732 (CE 1219)}

Overlijdens

Dorothea Feyte, geboren in 1690, trad binnen als moniale in 1714 . Ze overleed op 4 augustus of oktober 1731 .

\section{3 (CE 274)}

Overlijdens

Antonius Vivignies, profes van Luik, oud-prior van Brugge. Overleed in deze functie in Diest in mei 1732.

\section{Wijzigingen}

Gulielmus Damman, profes van Sint-Martens-Bos omstreeks 1686, werd in 1732 aangesteld als prior van Brugge en nu bevestigd in dit ambt.

Bernardus Garemijn, profes van Gent, wordt prior in Gent en werd daarvoor ontslagen als prior van Brugge.

\section{5 (CE 733)}

\section{Overlijdens}

Petrus Geersone, profes van Brugge in 1701, overleden als procurator op 31.3.1735.

Petronilla Geerts, geboren in 1683, trad in als donate in 1705 . Ze overleed op 10.10.1734.

\section{Wijzigingen}

Geen. 


\section{c. 1736 (CE 2320) \\ Overlijden \\ Geen.}

Wijzigingen

Geen.

\section{0 (CE 275)}

\section{Overlijdens}

Anthelmus Bosmans, profes van Diest, oud-vicaris van Sint-Anna (1728-1737) overleden als prior van Gent in 1739.

Carolus Lee, profes van Sheen op 27.12.1714, overleed als prior van Sheen op 20.4.1740.

Gulielmus Damman, profes van Sint-Martens-Bos, oud-prior van Brugge, overleed als coadjutor van zijn professiehuis in 1739/1740.

\section{Wijzigingen}

Andreas Bonne, profes van Brugge in 1728, wordt vicaris in Leuven. Hugo van Deuren, profes van Leuven in 1708, wordt vicaris in Brugge.

Thomas Yates, profes van Sheen in 1694, was coadjutor in Diest op het ogenblik dat hij tot prior verkozen werd van Sheen.

\section{c. 1741 (CE 2934)}

Overlijdens

Geen

\section{Wijzigingen}

Geen.

\section{2 (CE 276)}

\section{Overlijdens}

Franciscus van Einthoven, profes van Herne, overleed als vicaris van Sint-Anna in 1741/1742.

Hugo Hoebens, profes van Gent, oud-vicaris van Sint-Anna, overleden in Sint-Martens-Bos in 1741/1742.

Egidius Galle, donaat van Brugge voor 1692, overleed er in 1741/1742.

Josephus Cook, donaat van Sheen, overleed er op 26.10.1741. 


\section{Wijzigingen}

Josephus van Cauwenberghe, profes van Brugge, werd in 1741 aangesteld als vicaris van Herne en nu in deze functie bevestigd.

Petrus Orlemans, profes van Herne in 1711, werd door Révérend Père in december 1741 aangesteld als vicaris en overste van SintAnna en wordt nu in deze functie bevestigd.

\section{c. 1758 (CE 2512)}

Overlijdens

Bruno Hermans, antiquior en coadjutor van Lier, was prior van Brugge van 1729 tot 1730 . Hij overleed in Lier na 57 jaar kartuizerleven.

Colomba Beyaert, geboren te Sint-Winoksbergen in 1689, trad in als moniale in 1717 en stierf op 14 of 18 juni 1757 .

Lutgardis Dierickx, geboren te Brugge in 1693, trad als moniale binnen in 1715 . Ze overleed op 11 of 16 juni 1757.

\section{Wijzigingen}

Dominicus Eeraert, profes van Gent, werd in 1757 aangesteld als vicaris van Brugge. Hij wordt nu in deze functie bevestigd. Hij verving in Brugge Martinus Melaert, profes van Lier in 1744, die in 1757 benoemd werd tot rector van Sint-Martens-Bos.

Petrus Mus was sacrista van Brugge van 1752 tot 1757. Hij wordt nu hospes in Sheen.

Josephus Broeckaert, profes van Antwerpen, was hospes in Diest en gaat nu, eveneens als hospes, naar Brugge.

Carolus Tighe, profes van Sheen in 1748, wordt ook hospes in Brugge.

\section{c. 1760 (CE 2512)}

\section{Overlijdens}

Benedictus van Hecke, donaat van Brugge sedert 1733.

Barbara vander Steene, geboren in 1694, trad in als converse in 1717. Ze overleed op 20.12.1759.

\section{Wijzigingen}

Joannes-Baptista Luyckx, profes van Brussel in 1752, was vicaris van Sheen en wordt vicaris in Gent. Hij wordt in Sheen vervangen door Gilbertus Jump, profes van dat huis in 1726 , en die er reeds meermaals vicaris was. 


\section{c. 1762 (CE 2511)}

Overlijdens

Aloysius Blevin, profes van Sheen in 1730 , overleed er als procurator op 18.12.1761.

Thomas Whitefield, donaat van Sheen begin 1761, overleed er op 10 december van datzelfde jaar.

\section{Wijzigingen}

Nicolaus Albergati Liebaert, profes van Brugge in 1751, was er vicaris sinds 1759. Hij gaat nu als sacrista naar Diest. Hij wordt in Brugge als vicaris vervangen door Benedictus vanden Brule, profes van Lier. Joannes-Baptista Luyckx, vicaris van Gent, werd in 1761 prior van Sheen en wordt er nu bevestigd.

Jacobus Pierssens, profes van Brugge in 1723, was procurator van Gent en werd in 1761 aangesteld als procurator van Sheen. Hij wordt nu als zodanig bevestigd.

\section{c. 1765 (CE 2510)}

\section{Overlijdens}

Bernardus Garemyn, profes van Gent, was prior van Brugge van 1730 tot 1732. Hij overleed in Sint-Martens-Bos op 3.2.1765.

Laurentius Corneforth, profes van Sheen in 1753, stierf er op 2.11.1764.

\section{Wijzigingen}

Benedictus vanden Brule, vicaris van Brugge sinds 1762, vraagt met de meeste aandrang ontheven te worden en keert terug naar Lier, zijn huis van professie.

Josephus Laurens, profes van Brugge in 1750, vervangt hem als vicaris.

\section{c. 1766 (CE 2510)}

Overlijdens

Maria-Victoria Bart, geboren te Duinkerke op 22.7.1697, trad binnen als moniale eind 1726 . Ze was celleraria van 1733 tot 1751 en onderpriorin van 1751 tot 1764 . Ze overleed op 3.10.1765.

\section{Wijzigingen}

Josephus van Cauwenberghe, profes van Brugge in 1731, werd in 1765 benoemd tot procurator van Leuven en nu bevestigd. 


\section{c. 1767 (CE 2510)}

Overlijdens

Gulielmus Blevin, donaat van Sheen ca. 1730.

Angela de la Fontaine, geboren te Harelbeke op 9.8.1692, trad binnen als moniale in 1713 . Ze was sacrista van 1735 tot 1751 en celleraria van 1751 tot aan haar dood op 23.1.1767.

\section{Wijzigingen}

Hyacinthus Landry, profes van Nancy, was prior van Brugge sinds 1757. Hij wordt nu prior in Nancy.

De carta zegt verder: "De aanstelling van de nieuwe prior wordt overgelaten aan Reverendus Pater." Het zal Joannes-Baptista Luyckx worden.

Jacobus Pierssens, procurator van Sheen sinds 1761, wordt coadjutor in Brugge, zijn huis van professie.

Op het einde van de carta lezen we: "Deze carta moet gezonden worden naar Nieuwpoort, van Nieuwpoort naar Gent en vandaar teruggestuurd naar de Brugse monialen."

\section{c. 1768 (CE 1505)}

\section{Overlijdens}

Petrus Mus, profes van Brugge in 1749, overleed op 8.2.1768.

\section{Wijzigingen}

Joannes-Baptista Luyckx, in 1767 verkozen tot prior van Brugge, wordt nu bevestigd.

Martinus Staes verlaat zijn huis van professie Leuven om vicaris te worden te Brugge.

Benedictus vanden Brule, profes van Lier, werd vorig jaar 1767 vicaris van Sint-Anna en wordt nu bevestigd in deze functie.

\section{Ordinationes}

"Wij bevelen dat de monniken uit huizen binnen de stad gelegen slecht éénmaal per maand en wel de eerste week van elke maand een wandeling mogen maken buitenshuis. Ze moeten de kortste weg nemen naar de wallen, nergens afwijkend van die weg, maar rechtdoor naar buiten, en ze moeten op dezelfde wijze terugkeren."

Nota op het einde van de carta: "Deze uitgeschreven kopie moet naar Gent worden gestuurd, van Gent naar Brugge en Nieuwpoort en van Nieuwpoort naar de Brugse monialen waar ze moet bewaard worden." 


\section{c. 1770 (CE 1117)}

\section{Overlijdens}

Antonius Brabander, donaat van Brugge voor 1730, overleed er ca. 5.10 .1769 .

Jacobus Pierssens overleed als coadjutor van Brugge begin 1770 .

Joannes Geus, profes van Brugge in 1711, was er prior van 1738 tot 1742. Hij stierf er op 15.3.1770.

\section{Wijzigingen}

Antonius Le Lièvre, profes en vicaris van Antwerpen, wordt vicaris te Brugge en de vicaris van Brugge, Martinus Staes, vervangt hem als vicaris in Antwerpen.

\section{c. 1771 (CE 1108)}

Overlijdens

Geen.

\section{Wijzigingen}

Geen.

Een nota vooraan zegt: "Deze carta moet gezonden worden van Brussel naar Herne, van Herne naar Sint-Martens-Bos, van SintMartens-Bos naar Gent, van Gent naar Nieuwpoort, van Nieuwpoort naar de monniken van Brugge, dan naar de monialen waar ze moet blijven."

\section{c. 1772 (CE 1109)}

Overlijdens

Antonia de Gast, geboren in Oostkamp in 1717, trad in als donate in 1739. Ze overleed op 19.5.1771.

\section{Wijzigingen}

Amandus Opdenbergh, profes van Herne, procurator van Diest werd benoemd tot procurator van Sint-Anna in 1771 en nu bevestigd.

Bruno van Acker, profes van Gent, werd in 1771 vicaris van Brugge benoemd en nu bevestigd.

Antonius Le Lièvre, die vicaris was van Brugge, werd in 1771 naar Luik gestuurd in dezelfde functie en wordt nu bevestigd. 


\section{Conclusies}

Enkele conclusies dringen zich op.

De gelofte van stabiliteit zoals deze bestaat bij de benedictijnen en de cisterciënzers, bestaat niet bij de kartuizers. Een kartuizer blijft normaliter in zijn huis van professie, maar hij kan steeds verplaatst worden. Dit is het geval als hij niet goed aardt in dat bepaald klooster of als men hem nodig heeft in een ander huis of soms als straf. Ook komt het voor dat een monnik op eigen verzoek naar een ander huis mag gaan. In de zeventiende eeuw was het overplaatsen veel voorkomend, dit in tegenstelling tot de eerste eeuwen van het bestaan van de Orde.

In onze kartuizerprovincie, de Provincia Teutoniae of Dietse provincie, is dat in die periode dikwijls het geval. Meestal gaat het om 'officieren' die hun sporen verdiend hebben en daarom hulp gaan bieden in een ander monasterium. Enkele keren gaat het om 'moeilijke' monniken, die zich slecht aanpassen of zelfs duidelijk ongehoorzaam zijn. Het valt op dat dit weinig het geval is bij de conversen of donaten. Als deze verplaatst worden, dan is dat bijna altijd omdat ze hun kundigheid in andere huizen kunnen ten dienste stellen. Bovendien kunnen de contracten met de donaten niet vernieuwd worden als ze zich niet aanpassen aan de kloosterregel.

Wat eventuele taalproblemen betreft: zowel Engelstalige (afkomstig uit Sheen Anglorum) als Franstalige (meestal uit Luik) monniken komen naar Vlaamse kloosters en vice versa. We mogen dus aannemen dat de taal geen onoverkomelijk probleem stelt. De voertaal is zeker niet meer het Latijn (als dit het ooit geweest is), zelfs in de geschriften van die tijd wordt ze steeds minder gebruikt. Het aantal monniken uit andere kartuizerprovincies afkomstig, is evenwel vrij beperkt gebleven.

Noteren we ook dat het aantal permutaties niet gering was. Een uitzonderlijke benoeming is het noteren waard: in de carta 1724 wordt het overlijden gemeld van Anthelmus Verfaillie die, hoewel donaat en dus in principe niet gerechtigd een functie uit te oefenen in het convent, toch procurator van Brugge was van 1716 tot 1720 .

De monialen van Sint-Anna kregen als vicaris, procurator en coadjutor van zowat overal monniken en niet alleen uit Brugge, hoewel dit klooster dicht bij het hunne lag. Het is dus duidelijk dat de geestelijke waarde van de vicarissen, en enigszins ook de economische waar- 
de van de procuratoren, doorslaggevend zijn geweest bij hun benoemingen. De duur van hun verblijf bij de monialen is vaak vrij lang geweest.

Bij de zusters is het nogal opvallend dat de koormonialen vooral uit gegoede families komen, terwijl dat meestal niet het geval was bij de donaten. Doorgaans treden de meisjes in rond hun twintigste jaar, wat in die tijd vrij algemeen als de vereiste leeftijd werd aangezien. De Engelse kartuize Sheen Anglorum, aanvankelijk in Brugge, dan in Mechelen gevestigd en vanaf 1626 in Nieuwpoort, heeft vrij veel Vlaamse monniken gekregen. Dat is vooral gelegen aan het feit dat het voor dit klooster moeilijk was te rekruteren in Engeland. Om leefbaar te zijn moeten toch minstens zes koormonniken aanwezig zijn in een kartuis. We hebben op de moeilijkheden gewezen die dit klooster kende o.a. in de nota bij de carta 1696.

Hoewel de cartae aangezien worden als de basis voor het bepalen van de geschiedenis van de provincie en van de orde, hebben we toch moeten vaststellen dat er enkele fouten voorkomen in deze documenten. Dus moeten we ook met omzichtigheid omgaan met deze nochtans zeer waardevolle gegevens.

Uit de noten bij de cartae blijkt dat de exemplaren die we vonden bewaard werden bij de monialen.

De gegevens voorhanden in deze documenten laten bijna toe de volledige lijsten op te stellen van alle 'officieren' uit onze West-Vlaamse kartuizen. Zoals normaal te verwachten bij de kartuizers, omvatten hun monasteria doorgaans een twaalftal monniken; in Brugge was dat zo, in Sheen helemaal niet en bij de monialen zijn er meer religieuzen dan bij hun medebroeders.

En tenslotte nog dit: alle huizen van de Dietse provincie zijn steeds onderling betrokken geweest in de opbouw en de leiding van de verschillende huizen. Dit was in grote mate te danken aan het inzicht van de visitatoren. 
Index van alle voornamen en namen die voorkomen in de cartae.

Abraham Ellis 1637

Aerts 1653,1690

Aldegondis Brouckman 1677, 1702

Aloysius Blevin 1762

Amandus Denys 1682

Amandus Opdenbergh 1772

Ananias van Solten 1727

Andreas Bonne 1740

Andreas Jacobs 1661, 1662

Andreas vander Meeren 1654

Andreas van Langenhove 1730

Angela de la Fontaine 1767

Anna Berblock 1675

Anna de Boosere 1662

Anna Huerblock 1679

Anna van Crombrugghe 1630

Antonius le Lièvre 1770,1772

Antonius Langworth 1639

Antonia Aerts 1653

Antonius Brabander 1770

Antonia de Gast 1772

Anthelmus Bosmans 1740

Anthelmus Cottel 1673, 1677

Anthelmus de Veltere 1679, 1693, 1700

Anthelmus Queremans 1659

Anthelmus vander Plancken 1662

Anthelmus Verfaille 1724

Antonius du Lieu 1640, 1644, 1669

Antonius Naylor 1644, 1659

Antonius Tollenaere 1661

Antonius Vivignies 1727, 1728, 1733

Arnoldus 1638

Augustinus van Dorpe 1627, 1629

Baes 1702

Baker 1623

Barbara de Brune 1637

Barbara le Fer 1698

Barbara vander Steene 1760

Barnabas de Bergas 1682

Barnesly 1682

Baronaige 1619

Bart 1766

Bartholomeus Kellam 1637

Bartholomeus van Bauthem 1642

Bavo van Hulthem 1679

Benedictus Germees 1682

Benedictus van Hecke 1760
Benedictus vanden Brule 1762, 1765, 1768

Benedictus Vrancx 1662

Benedictus Wicart 1724

Berblock 1675

Bernadus d' Outelair 1662

Bernadus Garemijn 1733

Bernadus Ketelaere 1694

Bertinus Oliver 1621, 1628

Bertwisle 1673, 1677

Beyaert 1758

Bierewaert 1693

Bijl 1629, 1630, 1633, 1639

Bilcliffe 1662, 1669, I693

Blevin 17621767

Bodart 1669

Boele 1694

Bonaventura Rotsaert 1681

Bonne 1740

Bosman 1740

Brabander 1770

Braeckelman 1727

Brigham 1679

Broeckaert 1758

Brouckman 1661, 1677, 1702

Brow 1618

Bruneels 1659

Brumo Clement 1637, 1665

Bruno d'Avila 1679

Bruno de Cocq 1724

Bruno Emtinck 1633

Bruno Hermans 1790, 1758

Bruno Simons 1696, 1701

Bruno van Acker 1772

Buckenberg 1681

Cambrelin 1644

Campinck 1669

Carolus de Wolf 1642

Carolus Lee 1730, 1740

Carolus Tighe 1758

Carolus vander Guchte 1632, 1636

Carr 1618

Carron 1652

Catharina Bruneels 1659

Catharina Carron 1642

Catharina de Clercq 1632

Catharina Rosseels 1693 
Catharina Tilly 1659

Catharina Vrombaut 1632, 1639

Catharina Wautermans 1624

Catharina Wynckelman 1654

Charles 1626

Christianus Hazzard 1693

Christianus Weyts 1674,1675

Christina Brouckman 1677

Clara van Hondeghem 1644

Clara Verlinden 1660

Clarcke 1659

Clement 1637, 1665

Colomba Beyaert 1758

Columbanus Townley 1729

Constable 1670

Constantia du Persijn 1724

Constantinus Magnus 1675, 1693, 1702

Cook 1742

Cool 1665

Coolen 1659

Corneel Moens 1634

Corneforth 1765

Cornelia de Coninck 1664

Cornelis Jansonius van Schoonhoven 1621,1623

Cornelis Mertens 1626

Cornelis Rouberghere 1625, 1630

Cornelius le Roux 1631

Cottel 1673, 1677

d'Avila 1679

d' Outelair 1669, 1664, 1677

Dalton 1637

Damman 1733, 1740

Daniel Tuer 1620, 1623

Daniels 1630

David Lewis 1628

de Bergas 1682

de Bode 1633

de Boosere 1662

de Brune 1637

de Clercq 1632, 1728

de Cocq 1724

de Coninck 1664

de Gast 1772

de Grutere 1702

de la Fontaine 1767

de Paepe 1675, 1677

de Rycke 1679, 1694

de Simpol 1634 de Tollenaere 1674

de Veltere $1679,1693,1700$

de Villegas 1702

de Winte 1631

de Wolf 1642

de Wyen 1675

Denys 1682

Didacus Maldonata 1621

Dierickx 1758

Dionysius van Heumel 1682

Dominicus Eeraert 1758

Dorothea Feyte 1732

Dorothea Willems 1698

du Lieu 1640, 1644, 1665, 1669

du Persijn 1724

Duckett 1644

Edmundus Ireland 1653

Eduardus Fettiplace 1659

Eeraert 1758

Egidius de Winte 1631

Egidius Galle 1742

Egidius vanden Berghe 1679, 1700

Eglionby 1628

Elisabeth Forchout 1662

Elisabeth Foreest 1652

Elisabeth Pykevet 1621

Elisabeth van Gavere 1635

Elisabeth vander Leene 1689

Ellis 1637

Embertus Hellincx 1701

Emtinck 1633

Fennet 1627

Fettiplace 1659

Feyte 1732

Floyde 1631

Forchout 1662

Foreest 1652

Franciscus 1632

Franciscus Bodart 1669

Franciscus Braeckelman 1727

Franciscus de Rycke 1679, 1694

Franciscus Lambrechts 1639

Franciscus Thompson 1727

Franciscus Tou 1701

Franciscus van Einthoven 1742

Franciscus vander Meulen 1632, 1640

Frans Tilly 1659

Fredericus Fredrickx 1698

Fredericus Kogelkenius 1627 
Fredrickx 1698

Galle 1742

Garemijn 1733

Geersone 1735

Geerts 1728,1735

Gelos 1640

Georgius Brown 1618

Georgius Eglionby 1628

Georgius Hunter 1700, 1728

Georgius Sutrix 1681

Georgius Transam 1654

Gerardus Eligius Radelet 1621, 1638

Gerard 1652

Germees 1682

Geus 1770

Gilbertus Jump 1760)

Gindertaler 1631

Gisbertus Bijl 1630, 1639

Godelieve Le Maire 1694, 1698

Greene 1631

Gregorius Macquet 1665

Gregorius Raeymaeckers 1654

Guido Heynkens 1617, 1618

Gulielmus Blevin 1767

Gulielmus Damman 1733, 1740

Gulielmus Hall 1697

Gulielmus Skinner 1654

Gulielmus van Haecht 1623, 1661

Gulielmus vander Looven 1698

Hall 1697

Hallowes 1620, 1644

Hazzard 1693

Hellincx 1701

Hendrickx 1631

Henricus Bijl 1629, 1633

Henricus Petit 1677, 1694

Henricus Raeymaeckers 1694

Henricus Swinne 1725

Hermans 1730,1758

Herts 1681

Heynkens 1617, 1618

Hiëronymus Hoppenbrouwer 1682

Hiëronymus van Nijverseel 1696

Hiëronymus vanden Kerckhove 1689

Hoebens 1724, 1728, 1742

Holden 1623

Hoppenbrouwer 1682

Hostens 1694

Huerblock 1679
Hugo de Clercq 1728

Hugo Gelos 1640

Hugo Hoebens 1724, 1728, 1742

Hugo Pirot 1689, 1693, 1700, 1702

Hugo van Deuren 1740

Hugo van Gessel 1659, 1662

Hugo vander Straeten 1669

Hunter 1700,1728

Hutton 1628, 1630, 1634, 1637, 1640, 1641,1652

Hyacinthus Landry 1767

Ireland 1653

Jacoba de Grutere1702

Jacoba Olden 1628

Jacobs 1661, 1662, 1664

Jacobus Bertwisle 1673, 1677

Jacobus Boele 1694

Jacobus Cambrelin 1644

Jacobus Peeters 1727

Jacobus Pierssens 1762, 1767, 1770

Jansonius 1621, 1623

Janssen 1617

Jensema 1623

Joanna Sutiers 1634

Joanna Toris 1645

Joannes Baes 1702

Joannes Barnesby 1682

Joannes Baronaige 1619

Joannes Carr 1618

Joannes Cool 1665

Joannes Duckett 1644

Joannes Fennet 1627

Joannes Floyde 1631

Joannes Geerts 1728

Joannes Geus 1770

Joannes Hutton 1628, 1630, 1634, 1637,

$1640,1641,1652$

Joannes Marensis 1620

Joannes Oppers 1634

Joannes Pipenpoy 1636, 1654, 1682

Joannes Richard 1617

Joannes Sloyer 1631

Joannes Suertis 1620

Joannes-Antonius Garnet 1693

Joannes-Baptista Daniels 1630

Joannes-Baptista Luyckx 1760, 1762 ,

1767,1768

Joannes-Baptista vanHoorebeke 1695 , 1696,1702 
Joannes-Baptista Verstrepen 1681

Joannes-Baptista Wauwermans 1689

Joannes-Baptista Wouters 1696

Joly 1728

Josephus Betts 1730

Josephus Bierewaert 1693

Josephus Broeclaert 1758

Josephus Cook 1742

Josephus d' Outelair 1664, 1669, 1677

Josephus Keingiart 1698, 1701

Josephus Laurens 1765

Josephus Le Comte 1661

Josephus Scheldens 1628, 1633

Josephus Slade 1617

Josephus van Cauwenberghe 1742, 1766

Josephus van Hecke 1694

Josephus van Spiers 1702

Josephus van Thienen 1694

Josephus vander Hulst 1679

Judoca Verhelle 1677

Judocus Gindertaler 1631

Jump 1760

Justus de Paepe 1675, 1677

Keingiart 1698,1701

Kellam 1637

Ketelaere 1694

Knibbe 1621

Kogelkenius 1627

Lambrechts 1639

Landry 1767

Langhedul 1670

Langworth 1639

Laurens 1765

Laurentius Corneforth 1765

Le Comte 1661

Le Fer 1698

Le Lièvre 1770,1772

Le Maire 1694, 1698

Le Roux 1631

Lee 1730,1740

Lewis 1628

Liebaert 1762

Liranus 1631

Livina van Heylen 1702

Loones 1682

Ludwina Strobbe 1694

Lutgardis Dierickx 1758

Luyckx 1760, 1762, 1767, 1768

Macquet 1665
Magdalena Campinck 1669

Magdalena Janssen 1617

Magdalena Loones 1682

Magnus 1675, 1693, 1702

Mallory 1620

Marchand 1660

Marensis 1620

Maria de Tollenaere 1673

Maria de Villegas 1702

Maria Neyı 1630

Maria Sutiers 1634

Maria Tillemans 1659

Maria Tollenaere 1661

Maria Valentijn 1655

Maria van Munnekereede 1662

Maria Wouters 1681

Maria Wyen 1675

Maria-Victoria Bart 1766

Martinus Melaert 1758

Martinus Staes 1768, 1770

Melaert 1758

Melchior Charles 1626

Melchior Pletincx 1677

Mertens 1626

Michael Coolen 1659

Michael de Simpol 1634

Michael Wouters 1679

Moens 1634

Mus 1758,1768

Naylor 1659,1644

Neytz 1630

Nicolaus 1621

Nicolaus Albergati Liebaert 1762

Nicolaus Brouckman 1661, 1677

Nicolaus Hendrickx 1631

Nicolaus Marchand 1660

Norbertus Symons 1682

Octavianus vanden Bogaerde 1682, 1696

Olden 1629

Oliver 1621, 1628

Opdenbergh 1772

Oppers 1634

Orlemans 1742

Owst 1679

Passchier Sutiers 1634

Paulus van Hoorne 1670, 1673, 1679

Paulus vander Haeghen 1626, 1638

Peeters 1727

Petit 1677, 1694 
Petronilla Geerts 1735

Petronilla vande Walle 1670

Petrus Aerts 1690

Petrus Bilcliffe 1662, 1669, 1693

Petrus Brigham 1679

Petrus Constable 1670

Petrus Geersone 1735

Petrus Herts 1681

Petrus Langhedul 1670

Petrus Mus 1758, 1768

Petrus Orlemans 1742

Petrus Rolincx 1624

Petrus Vernoort 1620

Philippus Joly 1728

Pierssens 1762, 1767, 1770

Pipenpoy 1636, 1654, 1682

Pirot 1689, 1693, 1700, 1702

Pletincx 1677

Pykevet 1621

Radelet 1621, 1638

Raeymaeckers 1654, 1694

Richard 1617

Richardus Baker 1623

Robertus Clarke 1659

Robertus Dalton 1637

Robertus Holden 1623

Robertus Mallory 1620

Robertus Willasie 1694

Rolincx 1624

Rosseels 1693

Rotsaert 1681

Rouberghere 1625, 1630

Scheldens 1628, 1633

Schoonhoven 1621, 1623

Simon de Bode 1633

Simons 1696, 1701

Skinner 1654

Slade 1617

Sloyer 1631

Staes 1768,1770

Strobbe 1694

Suertis 1620

Sutiers 1634

Sutrix 1681

Swinne 1725

Symons 1682

Tghe 1758

Theresia Hostens 1694

Thomas Gerard 1652
Thomas Greene 1631

Thomas Hallowes 1620, 1644

Thomas Jensema 1623

Thomas Owst 1679

Thomas Thurold 1693, 1700

Thomas Whale 1693

Thomas Whitefield 1762

Thomas Yates 1740

Thompson 1727

Thurold 1693, 1700

Tillemans 1659

Tilly 1659

Tollenaere 1661

Toris 1644

Tou 1701

Townley 1729

Transam 1654

Tuer 1620,1623

Valentijn 1655

van Acker 1772

van Bauthem 1642

van Cauwenberghe 1742, 1766

van Crombrugghe 1630

van Deuren 1740

van Dorpe 1627, 1629

van Einthoven 1742

van Gavere 1635

van Gessel 1659

van Haecht 1623, 1661

van Hecke 1694, 1760

van Heumel 1682

van Heylen 1702

van Hondeghem 1644

van Hoorebeke 1695, 1696, 1702

van Hoorne $1670,1673,1679$

van Hulthem 1679

van Langenhove 1730

van Munnekereede 1662

van Nijverseel 1696

van Solten 1727

van Spiers 1702

van Thienen 1694

vande Walle 1670

vanden Berghe 1679, 1700

vanden Bogaerde 1682, 1696

vanden Brule 1762, 1765, 1768

vanden Kerckhove 1689

vander Guchte 1632, 1636

vander Haeghen 1626, 1638 
vander Hulst 1679

vander Leene 1689

vander Looven 1698

vander Meeren 1654

vander Meulen 1632, 1640

vander Plancken 1662

vander Steene 1760

vander Straeten 1669

Verfaillie 1724

Verhelle 1677

Verlinden 1660

Vernoort 1620

Verstrepen 1681

Victoria Bart 1766

Vincentius Knibbe 1621
Vivignies 1733

Vrancx 1662

Vrombaut 1632, 1639

Wautermans 1624

Wauwermans 1689

Weyts 1674,1675

Whale 1693

Whitefield 1762

Wicart 1724

Willasie 1694

Willems 1698

Willibrord Buckenberg 1681

Wouters 1679, 1681, 1696

Wynckelman 1654

Yates 1740

\section{Selectieve bibliografie}

BÖSEN W., Auf einsamer Strassen zu Gott. Freiburg, Herder, 1987.

BOERRIGTER E., en DE GRAUWE J., Meerhem Toen en Nu, Huize Sint-Jan de Deo Gent. Gent, 1991.

DE GRAUWE J., Chartreuse de Sainte-Anne-au-Désert à Bruges in: Monasticon Belge, dl. III, Province de Flandre Occidentale, vol. 4, Luik, 1978, p. 1263-1287.

DE GRAUWE J., Chartreuse du Val-de-Grâce à Bruges in: Monasticon Belge, dl. III, Province de Flandre Occidentale, vol. 4, Luik, 1978, p. 1191-1230.

DE GRAUWE J., Chartreuse de Sheen Anglorum à Nieuport in: Monasticon Belge, dl. III, Province de Flandre Occidentale, vol. 4, Luik, 1978, p. 1231-1262.

DE GRAUWE J., Prosopographia Cartusiana Belgica (1314-1796). Gent, 1976 (Analecta Cartusiana, 28).

DE GRAUWE J., Chartae Capitulorum Generalium 1655-1682. Salzburg, 1985 (Analecta Cartusiana, 100:13).

D'YDEWALLE S., De Kartuize Sint-Anna-ter-Woestijne te Sint-Andries en te Brugge 1350 1791. Brussel, s.d.(1945).

ESTHER J.P., DE GRAUWE J. en DESMET V., Het Kartuizerklooster binnen Brugge. Verleden en toekomst. Brugge, 1980.

HENDRICKX F., De handschriften van de Kartuis Genadedal bij Brugge (1318-1580) in: Ons Geestelijk Erf,47, 1973, p. 3-63, 241-290 en 48, 1974, p. 143-166. 
NUYTTENS M., Inventaris van het archief van de priorij van Sint-Martens-Bos te SintMartens-Lierde. Brussel, 1976.

Un Chartreux (=POSADA, G.), Maître Bruno, Père des Chartreux in: Analecta Cartusiana,115. Salzburg, 1990.

SCHOLTENS, H.J.J., Het kartuizerklooster Dal van Graciën buiten Brugge in: Handelingen van het Genootschap voor Geschiedenis 'Société d' Emulation' 83, 1940-1946, p. 133201.

SERROU R., Au désert de Chartreuse. La vie solitaire des fils de Saint-Bruno. Parijs, 1965.

VANDEMEULEBROUCKE J., De eerste jaren van de Kartuis 'Genadedal' te Sint-Kruis (1318-1324) in: Biekorf, 68, 1967, p.217-229. 
